
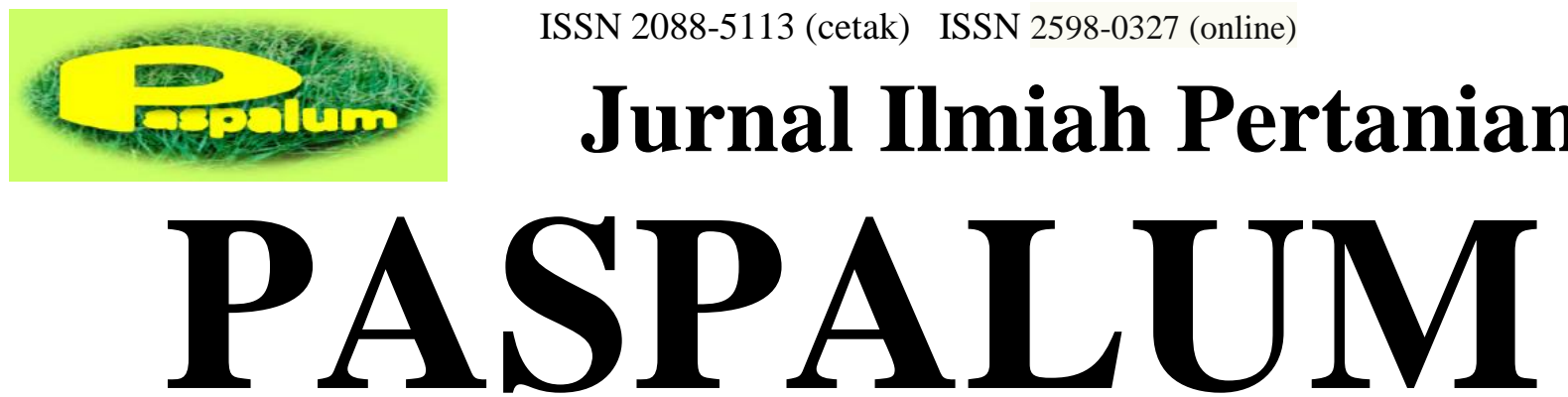

Volume. 6 No. 1 Bulan Maret Tahun 2018

http://journal.unwim.ac.id/index.php/paspalum

\title{
Analisis Penentuan Persediaan Singkong Sebagai Bahan Baku Tape Singkong Pada Agroindustri Peuyeum Abas Sawargi, Kecamatan Cimenyan, Kabupaten Bandung
}

\author{
Kuswarini Kusno, Annisaa Punjul Rahayu, Eti Suminartika, Anne Charina \\ Program Studi Aribisnis Fakultas Pertanian Unpad \\ rinipiano@gmail.com
}

Diterima tgl : 23-02-2018 dan disetujui untuk diterbitkan tgl : 31-03-2018

\begin{abstract}
Cassava as the third staple food for the people of Indonesia after rice and corn, is the raw material for making 'tape singkong”. Agroindustry Peuyeum Abas Sawargi located in District Cimenyan, Bandung Regency buy cassava almost every day to make "tape singkong”. It's not economical and inefficient; therefore good cassava inventory management is required. The purpose of this research was to determine the amount of economical cassava inventory and to know when to re-order the cassava so that the total cost of inventory to be a minimum, as well as comparing the actual cost of inventory to those based on economical cassava inventory. The research design was qualitative with case study technique. The collected data consists of primary data year 2017 and secondary data which were analyzed descriptively and quantitatively by Economic Order Quantity (EOQ) and Reorder Point (ROP) methods.. The results showed that the amount of cassava inventory that must be available was 3,264 $\mathrm{kg}$ with the frequency of ordering 61 times a year, while the re-ordering of cassava must be carried out when the remaining cassava stock of 2,240 kg. As a result, total inventory costs decreased by almost $48 \%$ within a year. Thus, the production process becomes more efficient and in the long run the agroindustry can be expected to be more competitive.
\end{abstract}

Key words : inventory management, economic order quantity, reorder point, cassava

\begin{abstract}
Abstrak
Singkong sebagai makanan pokok ke tiga masyarakat Indonesia setelah padi dan jagung merupakan bahan baku untuk tape singkong. Industri kecil Peuyeum Abas Sawargi yang terletak di Kecamatan Cimenyan, Kabupaten Bandung membeli singkong hampir setiap hari untuk membuat tape singkong. Itu tidak ekonomis dan tidak efisien; oleh karena itu dibutuhkan manajemen persediaan singkong yang baik. Tujuan penelitian ini adalah untuk mengetahui jumlah persediaan singkong yang ekonomis dan untuk mengetahui kapan pemesanan kembali singkong harus dilakukan agar biaya total persediaan minimal, serta membandingkan biaya total persediaan aktual dengan yang berdasarkan kuantitas pemesanan singkong yang ekonomis. Desain penelitian adalah kualitatif dengan teknik studi kasus. Data yang dikumpulkan terdiri dari data primer tahun 2017 dan data sekunder yang dianalisis secara deskriptif an kuantitatif dengan metode Economic Order Quantity (EOQ) dan metode Reorder Point (ROP). Hasil penelitian menunjukkan bahwa jumlah persediaan singkong yang harus tersedia adalah $3.264 \mathrm{~kg}$ dengan frekuensi pemesanan $61 \mathrm{kali}$ dalam setahun, sedangkan pemesanan kembali singkong harus dilakukan pada saat jumlah persediaan singkong tersisa $2.240 \mathrm{~kg}$. Akibatnya, biaya total persediaan berkurang hampir $48 \%$ dalam satu tahun. Dengan demikian proses produksi menjadi lebih efisien dan dalam jangka panjang agroindustri ini diharapkan bisa menjadi lebih kompetitif.
\end{abstract}

Kata kunci : manajemen persediaan, economic order quantity, reorder point, singkong 


\section{PENDAHULUAN}

Indonesia merupakan salah satu negara penghasil singkong terbanyak di dunia. Menurut Pusat Data dan Sistem Informasi Pertanian (2015), Negara Indonesia merupakan negara dengan tingkat produksi singkong terbanyak ke empat di dunia setelah Nigeria, Thailand, dan Brazil. Dari tahun 2009 hingga tahun 2013, Indonesia mempunyai kontribusi sebesar $9,17 \%$ terhadap produksi singkong dunia atau produksi rataratanya mencapai 23,62 juta ton umbi basah setiap tahunnya (Gambar 1). Selain itu, singkong juga merupakan panganan utama bagi masyarakat Indonesia. Menurut Pusat Data dan Sistem Informasi Pertanian, 2015, singkong merupakan makanan pokok ke tiga setelah padi dan jagung dan sebagai alternative nasional (Bargumono dkk, 2013)..

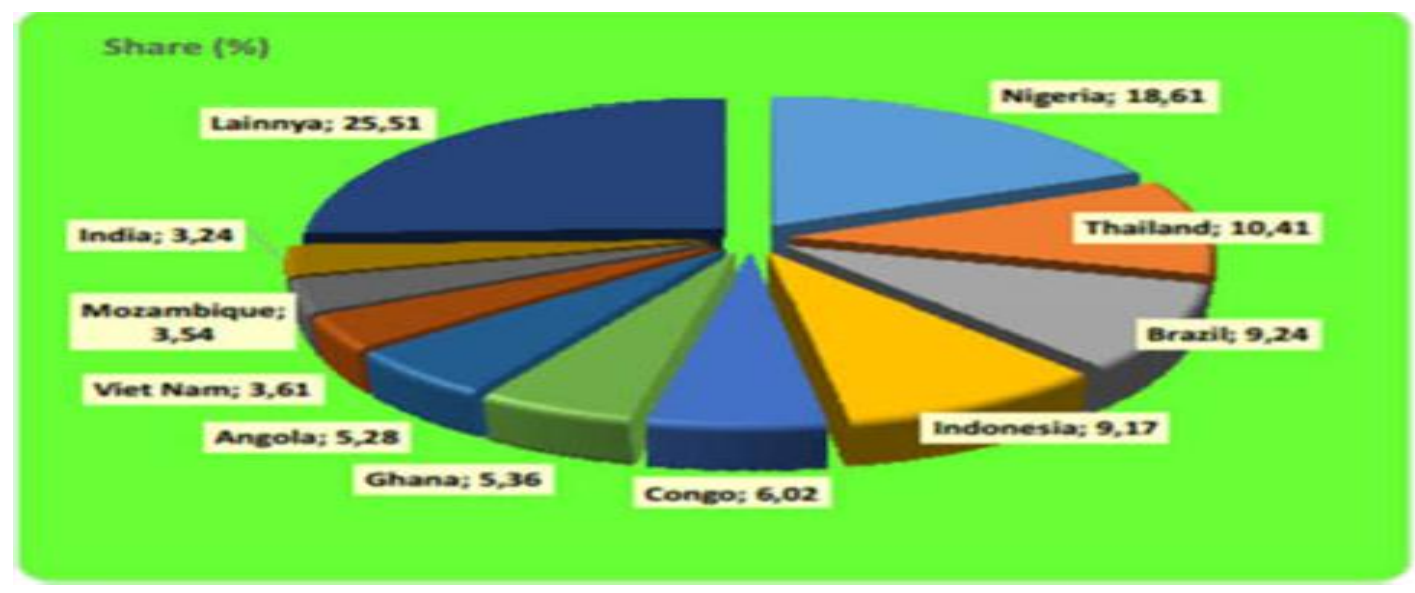

Gambar 1. Sepuluh Negara Sentra Produksi Singkong Dunia, Rata-rata Tahun 2009-2013 Sumber : Pusat Data dan Sistem Informasi Pertanian (2015)

Selain dikonsumsi secara langsung, singkong juga dapat dijadikan berbagai macam produk olahan. Di Indonesia terdapat banyak produk olahan yang berbahan baku singkong, seperti gaplek, tepung tapioka, tepung gaplek, tiwul, keripik, tapioka mutiara, dan tape singkong atau peuyeum.

Dengan beragamnya jenis produk olahan yang dapat diproduksi dari singkong, maka terbuka peluang bagi masyarakat untuk memulai usaha rumah tangga berbasis agroindustri. Menurut Saragih (2001), agroindustri merupakan salah satu subsistem penting dalam sistem agribisnis yang memiliki potensi untuk mendorong pertumbuhan ekonomi disebabkan oleh pangsa pasar dan nilai tambah yang relatif besar dalam produksi nasional. Agroindustri dinilai dapat mempercepat transformasi struktur perekonomian dari pertanian ke industri dan dapat menjadi wahana bagi usaha pengentasan kemiskinan karena daya jangkau serta spektrum kegiatannya yang luas. Sektor agroindustri memiliki potensi untuk menjadi penggerak perekonomian karena produk agroindustri memiliki elastisitas harga untuk permintaan dan penawaran yang relatif lebih tinggi sehingga tidak mungkin terjadi pelambatan. Berbeda dengan barang primer atau produk pertanian yang belum diolah, jika terjadi panen raya maka harga akan turun disebabkan oleh elastisitas harga yang rendah

Terutama di daerah Bandung, tape singkong merupakan produk oleh-oleh yang banyak dibeli oleh pelancong yang datang ke kota Bandung. Salah satu daerah penghasil tape singkong di Bandung adalah Kecamatan Cimenyan. Di Kecamatan Cimenyan ini terdapat pembuat tape singkong yang memproduksi secara kontinu dan ada pula yang memproduksi tape singkong secara musiman atau hanya memproduksi tape pada saat jumlah singkong melimpah. Pembuat tape singkong musiman tidak memproduksi tape secara tetap dan jumlah yang dihasilkan pun lebih sedikit dibandingkan dengan pembuat tape yang memproduksi secara kontinu atau tetap. Terdapat 4 pembuat tape singkong terbesar di Cimenyan, namun yang memiliki jumlah produksi terbanyak adalah agroindustri Peuyeum Abas Sawargi, seperti dapat dilihat pada Tabel 1. 
Tabel 1. Pembuat Tape Singkong di Kecamatan Cimenyan yang Memproduksi Secara Kontinu

\begin{tabular}{ccc}
\hline $\begin{array}{c}\text { Pemilik } \\
\text { Usaha Tape } \\
\text { Singkong }\end{array}$ & Lokasi & $\begin{array}{c}\text { Rata-rata } \\
\text { Produksi } \\
\text { Tape } \\
\text { Singkong } \\
\text { (kg/hari) }\end{array}$ \\
\hline Dede & $\begin{array}{c}\text { Kampung } \\
\text { Kasimukan } \\
\text { Kampung } \\
\text { Cacah } \\
\text { Kampor } \\
\text { Suryani } \\
\text { Abas }\end{array}$ & 600 \\
Tatang & $\begin{array}{c}\text { Kabakan } \\
\text { Kampung } \\
\text { Cipaheut }\end{array}$ & 1000 \\
Ridwan & 400 \\
\hline
\end{tabular}

Sumber : Kantor Desa Cimenyan (2017)

Selain memproduksi tape singkong lebih banyak dibandingkan dengan yang lainnya, Peuyeum Abas Sawargi pun lebih berinovasi dalam membuat kemasan dan memiliki label. Tape tidak hanya dijual di dalam carangka atau keranjang besar saja, namun juga dijual di dalam besek kecil yang berisikan $1 \mathrm{~kg}$ tape, sementara usaha tape lainnya masih menjual dalam bentuk keranjang besar saja

Dalam sehari, agroindustri ini memproduksi ratarata $900 \mathrm{~kg}$ hingga $1000 \mathrm{~kg}$ tape singkong. Dengan banyaknya permintaan tape singkong setiap harinya, Peuyeum Abas Sawargi membutuhkan 500 kg - 1.200 $\mathrm{kg}$ singkong per hari. Jenis singkong yang digunakan adalah jenis kedapo, mentega, dan manggu. Biasanya singkong dibeli di daerah Padalarang, Subang, dan Cimenyan dengan sistem beli per kilo atau borongan. Yang dimaksud sistem borongan adalah membeli tanaman singkong yang belum dipanen di kebun dan jumlah singkongnya hanya bisa ditaksir saja. Sistem pembelian borongan ini diterapkan di daerah Cimenyan, sedangkan untuk di daerah Padalarang dan Subang biasanya secara kiloan. Walaupun kebun singkong di daerah Cimenyan lebih dekat dengan tempat produksi agroindustri Peuyeum Abas Sawargi, namun sayangnya ketersediaan singkong di daerah Cimenyan tidak stabil dan bergantung musim. Oleh karena itulah Peuyeum Abas Sawargi lebih sering membeli singkong di daerah Padalarang atau Subang yang ketersediaan singkongnya lebih stabil. Peuyeum Abas Sawargi memiliki 4 orang mitra di Padalarang yang bertugas untuk mencarikan singkong yang akan dibeli. Singkong yang dibeli akan diambil sendiri oleh pihak Peuyeum Abas Sawargi degan menggunakan mobil pick up, dan pembelian singkong dilakukan hampir setiap hari.

Pembelian singkong yang dilakukan hampir setiap hari oleh itu tidak ekonomis karena dapat menghabiskan waktu dan biaya secara tidak efisien. Hal ini disebabkan Peuyeum Abas Sawargi belum memiliki manajemen persediaan singkong. Selain menghabiskan biaya, tidak adanya manajemen persediaan juga dapat berisiko untuk menghambat proses produksi. Apabila permintaan tape tiba-tiba melonjak atau jumlah bahan baku singkong kurang, agroindustri tersebut tidak memiliki persediaan singkong yang dapat digunakan untuk produksi. Manajemen persediaan bahan baku penting untuk dimiliki oleh suatu usaha, seperti yang diungkapkan Fahmi (2012) bahwa manajemen persediaan dapat mengatur dan mengelola setiap kebutuhan bahan baku agar selalu tersedia, baik dalam kondisi pasar yang stabil maupun berfluktuasi.

Oleh karena itu, dibutuhkan manajemen persediaan dan sistem pemesanan kembali singkong yang dapat meminimumkan biaya persediaan bagi agroindustri Peuyeum Abas Sawargi.

Berdasarkan pemaparan di atas, tujuan dari penelitian ini adalah untuk mengetahui : 1) jumlah persediaan singkong yang ekonomis pada agroindustri Peuyeum Abas Sawargi; 2) waktu yang tepat bagi agroindustri tersebut untuk melakukan pemesanan kembali singkong; dan 3) membandingkan biaya total persediaan aktual dengan yang berdasarkan model EOQ.

\section{METODE PENELITIAN}

Objek dari penelitian ini adalah manajemen persediaan singkong pada agroindustri Peuyeum Abas Sawargi, yaitu kuantitas persediaan singkong yang ekonomis serta waktu pemesanan kembali singkong 
yang meminimumkan biaya persediaan total. Agroindustri ini berlokasi di Kecamatan Cimenyan, Kabupaten Bandung. Desain penelitian menggunakan desain kualitatif dengan teknik penelitian studi kasus.

Data yang dikumpulkan berasal dari sumber primer dan sekunder. Data primer diperoleh melalui wawancara yang mendalam dan tidak terstruktur dengan 4 informan yakni pemilik agroindustri Peuyeum Abas Sawargi dan 3 orang pengelola usaha yang terdiri dari 2 orang anak pemilik dan 1 orang menantu dari pemilik. Selain itu juga dilakukan observasi lapangan ke tempat produksi tape singkong untuk mempelajari alur proses produksinya. Sementara itu, data sekunder diperoleh dari catatan milik agroindustri tersebut.

Variabel yang dianalisis dalam penelitian ini adalah:

1. Karakteristik tape singkong yang meliputi: Jumlah singkong yang digunakan, jenis bahan baku, jumlah ragi yang digunakan dalam 1 kali proses produksi, jenis peralatan yang digunakan, jumlah tenaga kerja, upah tenaga kerja, jam kerja tenaga kerja, tahapan proses produksi, kuantitas tape singkong, serta pemasaran tape singkong.

2. Manajemen persediaan meliputi: a) perencanaan persediaan singkong yang terdiri dari jumlah dan frekuensi pemesanan singkong; b) Biaya yang terdiri dari biaya penyimpanan, biaya pemesanan, dan biaya pembelian singkong.

Analisis terhadap data terdiri dari tahapan berikut:

1. Menggambarkan jalannya usaha, manajemen persediaan dan pemasaran singkong yang dilakukan secara deskriptif.

2. Menghitung jumlah persediaan singkong yang ekonomis dengan menggunakan model EOQ yang rumusnya sebagai berikut:

$$
\mathrm{EOQ}=\sqrt{\frac{2 \mathrm{RS}}{\mathrm{c}}}
$$

dimana,

$\mathrm{EOQ}=$ jumlah pemesanan singkong yang ekonomis $(\mathrm{kg})$

$$
\begin{aligned}
\mathrm{R} & =\text { jumlah pembelian singkong per pemesanan } \\
(\mathrm{kg}) & \text { biaya simpan singkong per } \mathrm{kg}(\mathrm{Rp}) \\
\mathrm{C} & =\text { biay pemesanan per pesanan }(\mathrm{Rp})
\end{aligned}
$$

3. Menentukan waktu yang tepat untuk pemesanan ulang singkong dengan rumus ROP:

dimana,

$$
\mathrm{ROP}=(\mathrm{d} \times \mathrm{L})+\mathrm{SS}
$$

ROP $=$ Reorder point (titik pemesanan kembali) ( $\mathrm{kg})$

$\mathrm{d} \quad=$ jumlah singkong yang dibutuhkan ( $\mathrm{kg} /$ pemesanan)

$\mathrm{L} \quad=$ Lead time atau waktu tenggang (hari)

SS = Safety stock atau jumlah singkong minimum $(\mathrm{kg})$

4. Menentukan frekuensi pemesanan singkong optimal (F) dengan rumus:

$$
\mathrm{F}=\frac{\text { Total pembeliansingkong setahun }}{\text { EOQ }}
$$

5. Menghitung biaya total persediaan dengan rumus:

$$
\mathrm{TC}=\frac{\mathrm{R}}{\mathrm{Q}} \mathrm{xS}+\frac{\mathrm{Q}}{2} \mathrm{xC}
$$

dimana,

$$
\mathrm{TC}=\text { biaya total persediaan }
$$

\section{HASIL DAN PEMBAHASAN}

\section{Keadaan Umum Agroindustri}

Agroindustri Peuyeum Abas Sawargi merupakan usaha rumah tangga yang didirikan sejak tahun 1970 oleh Bapak Abas yang terletak di Jalan Babakan Cimenyan, RT 05, RW 03, Kampung Babakan Cimenyan, Desa Cimenyan, Kecamatan Cimenyan, Kabupaten Bandung. Agroindustri ini dikelola oleh keluarga yaitu 3 orang anak dan 1 orang menantu Bapak Abas, serta 5 orang pegawai pembuat tape singkong, dan 4 orang pegawai yang menyediakan bahan baku singkong.

Bahan baku singkong yang digunakan untuk membuat tape adalah singkong jenis manggu dan mentega. Kedua jenis singkong ini dipilih karena rasanya legit sehingga menghasilkan tape singkong 
yang kenyal dengan warna kuning keemasan. Dalam pembelian singkong, terdapat beberapa proses yang dilakukan, seperti tampak pada Gambar 2.

Pembelian singkong dilakukan oleh 4 orang pegawai yang begitu selesai melakukan tugasnya, langsung diberi upah sebesar Rp100.000 per orang. Singkong diangkut menggunakan mobil pick up yang ditutup terpal agar tidak jatuh tercecer dan tidak terkena hujan. Para pegawai biasanya mencari singkong di daerah Padalarang, Subang, dan Cimenyan.

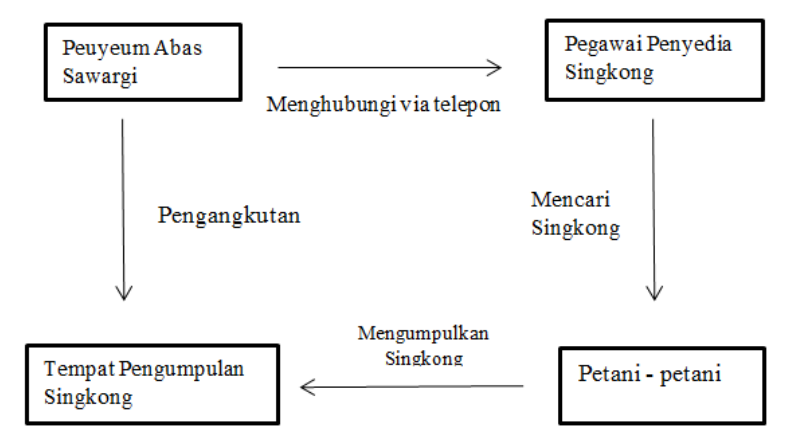

Gambar 2. Alur Proses Pembelian Singkong

Di daerah Padalarang dan Subang ketersediaan singkongnya stabil, sedangkan di daerah Cimenyan tidak stabil karena bergantung pada musim, dimana singkong yang dihasilkan pada musim hujan lebih banyak dari pada musim kemarau. Harga singkong Rp 2000 per kilogram untuk jenis singkong mangu ataupun mentega. Harga tersebut stabil dari tahun 2016 hingga Agustus 2017.

Dalam membuat tape singkong, dibutuhkan beberapa bahan baku penunjang, yaitu air dan ragi. Air yang digunakan adalah air bersih yang diperoleh dari mata air yang mengaliri daerah Kampung Babakan Cimenyan. Sedangkan untuk bahan baku penunjang ragi diperoleh dari pemasok yang mengirim ragi sebulan sekali. Proses pembuatan tape singkong dapat dilihat pada Gambar 3.

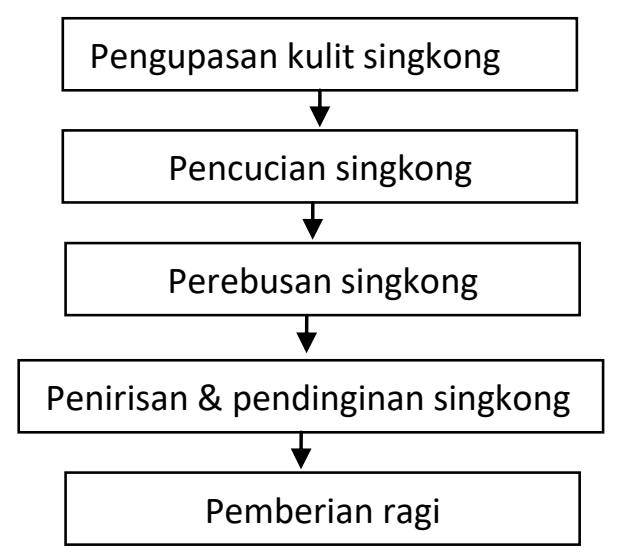

Gambar 3. Alur Pembuatan Tape Singkong

Singkong yang sudah diberi ragi perlu didiamkan selama 2-3 hari untuk proses fermentasi. Selanjutnya tape singkong dikemas lalu dijual. Terdapat 2 jenis kemasan tape singkong yaitu besek kecil dan keranjang besar yang disebut carangka. Dalam kemasan besek kecil berisi $1 \mathrm{~kg}$ tape singkong, sedangkan di dalam carangka dapat dimuat $40-50$ $\mathrm{kg}$ tape singkong. Harga tape singkong kemasan besek kecil adalah Rp12.500/kg sedangkan dalam carangka $\mathrm{Rp} 10.000 / \mathrm{kg}$.

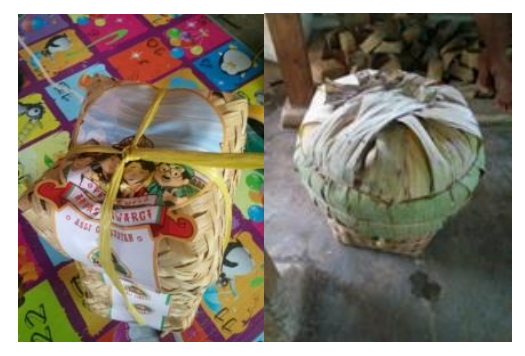

Gambar 4. Kemasan Tape Singkong 
Konsumen yang membeli dalam kemasan carangka adalah konsumen yang membutuhkan tape singkong dalam jumlah banyak, seperti pemilik toko kue dan pemilik toko oleh-oleh. Sedangkan konsumen yang membeli dalam kemasan besek merupakan konsumen yang akan mengonsumsi sendiri atau dijadikan buah tangan khas Kota Bandung. Penggunaan besek ini memudahkan konsumen karena tape singkong yang akan dibeli tidak perlu ditimbang lagi sesuai dengan jumlah yang diinginkan; melainkan konsumen tinggal mengambil beberapa besek sesuai yang dibutuhkan.

Agroindustri Peuyeum Abas Sawargi menjual produknya ke toko oleh-oleh di Jalan Pasteur, Jalan Buah Batu, Jalan Kopo, dan kios di rest area Tol Cipularang Km 97 dan Km 57, serta toko kue Kartika Sari. Agroindustri ini tidak mengantar pesanan kepada semua toko, melainkan ada yang mengambil sendiri pesanannya ke tempat produksi. Toko kue yang pesanannya selalu diantarkan adalah Kartika Sari; diantarnya ke Kartika Sari Pusat di Jalan Pasirkaliki, Bandung. Pengantaran tape singkong ke Kartika Sari itu rutin dilakukan pada pagi hari karena tape singkong tersebut akan diolah lagi menjadi kue tertentu. Untuk suplai ke kios di rest area, pihak agroindustry mengantarkan hanya sampai ke rumah pemilik kios yang beralamat di Jalan Putri, Bandung.

Tape singkong yang telah dikirim dan dibeli akan langsung dibayar pada saat itu juga, dan pihak toko akan memberi tahu jumlah tape singkong yang dibutuhkan keesokan harinya melalui telepon ataupun secara langsung saat melakukan transaksi.

\section{Manajemen Persediaan Singkong}

Persediaan adalah kemampuan suatu perusahaan dalam mengatur dan mengelola setiap kebutuhan barang baik barang mentah, barang setengah jadi dan barang jadi agar selalu tersedia baik dalam kondisi pasar yang stabil maupun berfluktuasi (Fahmi, 2012). Dalam penelitian ini, jumlah persediaan singkong dihitung untuk 1 bulan karena umbi singkong hanya dapat disimpan selama 1 hingga 2 bulan dengan menggunakan teknik penyimpanan tertentu (Pudatin, 2015).

Peuyeum Abas Sawargi menyimpan singkong di tanah kosong kira-kira seluas $1 \mathrm{~m}^{2}$. Kemudian singkong tersebut dilindungi oleh terpal tebal. Cara penyimpanan seperti ini membuat singkong hanya bertahan 3 hari. Karena itu Peuyem Abas Sawargi perlu mengubah cara penyimpanan antara lain dengan kotak kayu yang dialasi pasir, atau serbuk gergaji atau sekam yang lembab (Pusat Data dan Sistem Informasi Pertanian, 2015)

Untuk menentukan jumlah persediaan ini diperlukan data jumlah pembelian singkong, biaya pemesanan per pesanan, biaya penyimpanan singkong per kilogram, serta harga singkong per kilogram. Jumlah pembelian singkong dapat dilihat pada Tabel 2.

Tabel 2. Jumlah Pembelian Singkong dan Frekuensi Pembelian Singkong Tahun 2016

\begin{tabular}{ccc}
\hline Bulan & $\begin{array}{c}\text { Frekuensi } \\
\text { Pembelian } \\
\text { (kali) }\end{array}$ & $\begin{array}{c}\text { Jumlah } \\
\text { Pembelian } \\
\text { Singkong (kg) }\end{array}$ \\
\hline Januari & 19 & 16.650 \\
Februari & 16 & 14.000 \\
Maret & 19 & 15.725 \\
April & 17 & 16.250 \\
Mei & 18 & 16.150 \\
Juni & 17 & 15.800 \\
Juli & 19 & 18.100 \\
Agustus & 18 & 17.050 \\
Septembe & 17 & 15.200 \\
r & 15 & 18.050 \\
Oktober & 18 & 18.025 \\
Novembe & & 17.750 \\
r & 21 & 198.750 \\
Desember & 214 & 16.562 \\
Total & 18 &
\end{tabular}


Tabel 2 memperlihatkan bahwa total pembelian singkong selama tahun 2016 adalah $198.750 \mathrm{~kg}$ dengan rata-rata $16.562 \mathrm{~kg}$ per bulan. Frekuensi pemesanan singkong selama setahun yaitu 214 kali, Frekuensi pemesanan rata-ratanya per bulan sebanyak 18 kali. Jadi, rata-rata pembelian singkong dalam sekali pemesanan adalah $6.562 \mathrm{~kg}$ dibagi $18 \mathrm{kali}$ atau sebanyak $920 \mathrm{~kg}(=\mathrm{R})$.

\section{- Biaya Pemesanan Singkong per Sekali Pesan}

Biaya pemesanan yang dikeluarkan terdiri dari biaya transportasi, biaya telepon, dan upah pekerja penyedia singkong. Biaya transportasi merupakan biaya yang dikeluarkan untuk BBM (Bahan Bakar Minyak) kendaraan mobil pick up yang digunakan untuk mengangkut umbi singkong yang telah dipesan. Setiap bulannya Peuyeum Abas Sawargi telah menganggarkan biaya untuk BBM kendaraan tersebut. Tabel 3 menyajikan biaya BBM selama tahun 2016.

Dari Tabel 3 dapat diketahui bahwa biaya transportasi sebesar Rp 38.000.000 untuk membeli umbi singkong selama setahun, dan rata-rata per bulannya sebesar $\mathrm{Rp}$ 3.166.667. Kemudian biaya transportasi dalam sekali pemesanan dapat diketahui dengan cara membagi rata-rata biaya BBM per bulan

Tabel 3. Biaya Transportasi Tahun 2016

\begin{tabular}{cc}
\hline Bulan & Biaya Transportasi (Rp) \\
\hline Januari & 3.500 .000 \\
Februari & 3.000 .000 \\
Maret & 3.500 .000 \\
April & 3.000 .000 \\
Mei & 3.000 .000 \\
Juni & 3.000 .000 \\
Juli & 3.500 .000 \\
Agustus & 3.000 .000 \\
September & 3.000 .000 \\
Oktober & 3.000 .000 \\
November & 3.000 .000 \\
Desember & 3.500 .000 \\
Total & 38.000 .000 \\
Rata-rata & 3.166 .667 \\
\hline
\end{tabular}

Sumber: Peuyeum Abas Sawargi (2016)

dengan rata-rata frekuensi pembelian per bulan; yakni Rp 3.166.667 dibagi $18 \mathrm{kali}$, atau sama dengan $\mathrm{Rp}$ 175.926 untuk setiap kali pemesanan.

Yang dimaksud biaya telepon di sini adalah biaya pulsa yang dikeluarkan untuk menghubungi pekerja yang bertugas menyediakan singkong. Provider yang digunakan adalah Telkomsel yang memiliki tarif 390 rupiah per 15 detik, sedangkan rata-rata waktu yang dibutuhkan untuk menelepon pekerja dalam sekali pemesanan adalah 2 menit. Dengan demikian dalam sekali pemesanan singkong dikenakan tarif sebesar Rp 3.120 .

Upah pekerja penyedia singkong juga termasuk ke dalam biaya pemesanan karena biaya upah tersebut baru dikeluarkan ketika agroindustri melakukan pemesanan singkong. Upah yang dibayarkan kepada para pekerja ini sebesar Rp 100.000 per orang. Karena terdapat 4 orang pekerja maka total upah yang dibayarkan dalam sekali pemesanan singkong adalah sebesar Rp 400.000.

Jadi, total biaya pemesanan untuk sekali memesan singkong adalah : Rp $175.926+$ Rp $3.120+$ Rp 400.000 $=\operatorname{Rp} 579.046(=\mathrm{S})$.

\section{- Biaya Penyimpanan Singkong per Kilogram}

Biaya penyimpanan singkong tidak menentu setiap bulannya. Hal ini disebabkan jumlah singkong yang disimpan setiap bulan tidak selalu sama. Oleh karena itu biaya penyimpanan dihitung per kilogram. Peuyeum 
Abas Sawargi melakukan anggaran biaya simpan sebesar 5\% dari setiap kilogram singkong yang disimpan. Biasanya anggaran ini lebih sering digunakan untuk mengganti kerusakan singkong yang rusak akibat penyimpanan. Dengan harga singkong per kilogram sebesar Rp 2000 maka biaya simpannya menjadi Rp100 per kilogram (= C)

\section{Jumlah Persediaan Singkong yang Ekonomis}

Selanjutnya jumlah persediaan atau pemesanan singkong yang ekonomis dapat diperoleh dengan rumus (1) di atas:

$$
E O Q=\sqrt{\frac{2 R S}{C}}=\sqrt{\frac{2(920)(579.046)}{100}}=3.264
$$

Dengan demikian, jumlah pemesanan singkong yang ekonomis adalah $3.264 \mathrm{~kg}$. Singkong ini disimpan untuk digunakan pada proses produksi selanjutnya. Jadi, Peuyeum Abas Sawargi tidak perlu melakukan pemesanan singkong setiap kali akan melakukan proses produksi. Jika agroindustry ini mengikuti hasil perhitungan EOQ ini, biaya persediaan menjadi berkurang; tentunya apabila tempat dan cara penyimpanan singkong sudah baik dan benar sehingga lama penyimpanan bisa mencapai $1-2$ bulan.

Dalam menerapkan EOQ, terdapat asumsi yang harus dipenuhi sebagai berikut: Permintaan akan produk adalah konstan, seragam dan diketahui (deterministik).

1.Harga per unit produk adalah konstan.

2.Biaya penyimpanan per unit per tahun (C) adalah konstan.

3.Biaya pemesanan per pesanan (S) adalah konstan.

4.Waktu antara pesanan dilakukan dan barang-

barang diterima (lead time) adalah konstan.

5.Tidak terjadi kekurangan barang atau (back orders).

Untuk menyimpan singkong, ada beberapa teknik penyimpanan yang dapat memperpanjang masa simpan singkong (Ginting, 2002):

1. Dengan media serbuk gergaji atau sekam yang lembab. Pada teknik ini, dibutuhkan kotak kayu untuk menyimpan singkong. Kotak kayu ini perlu dilapisi plastik pada permukaannya, setelah itu dilakukan penyimpanan singkong dengan cara berlapis-lapis antara umbi singkong dengan serbuk gergaji ataupun sekam. Pada dasar kotak dimasukkan serbuk gergaji atau sekam terlebih dahulu, lalu masukkan singkong, lalu ditutupi lagi menggunakan serbuk gergaji atau sekam, proses tersebut dapat dilakukan hingga singkong memenuhi kotak penyimpanan. Teknik penyimpanan ini dapat menyimpan singkong selama 1 bulan. Serbuk gergaji dan sekam yang lembab dapat menghambat proses penguapan air sehingga kesegarannya relatif tetap. Dengan tertutupnya ubikayu oleh serbuk gergaji ataupun sekam, reaksi oksidasi yang menyebabkan pewarnaan juga dapat dihindari.

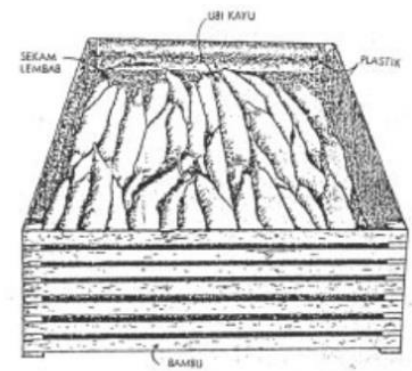

Gambar 4. Kotak Kayu Penyimpanan Singkong Sumber : Badan Penelitian Aneka Kacang dan Umbi (Ginting, 2002)

2. Dengan media pasir. Teknik penyimpanan singkong ini dapat dilakukan pada bak yang terbuat dari susunan batu bata yang dasarnya ditutupi oleh pasir kering setebal $5 \mathrm{~cm}$. Penyimpanan singkong ini dilakukan dengan cara berlapis-lapis antara singkong dengan pasir. Singkong diletakkan di atas pasir lalu ditutupi dengan pasir lagi setebal $5 \mathrm{~cm}$, proses ini dapat dilakukan berulang-ulang hingga singkong memenuhi isi bak penyimpanan. Setelah itu di atas pasir ditutup lagi dengan batu bata dan yang terakhir ditutup seng. Pada penyimpanan seperti ini, bak batu bata harus didirikan pada tempat yang aman serta tidak terkena air hujan dan teknik penyimpanan ini dapat menyimpan singkong selama $1-2$ bulan.

\section{Pemesanan Kembali Singkong}

Menurut Assauri (2004), tingkat pemesanan kembali (reorder point) adalah suatu titik atau batas dari jumlah persediaan yang ada pada suatu saat dimana pemesanan harus diadakan kembali. Untuk mengetahui waktu yang tepat bagi Peuyeum Abas Sawargi untuk 
mengadakan pemesanan kembali singkong digunakan model ROP dengan rumus (2) di atas. Untuk itu, perlu diketahui tingkat kebutuhan singkong, lead time atau waktu yang dibutuhkan untuk mendapatkan singkong dari saat memesan hingga sampai di tempat produksi, serta safety stock atau persediaan pengamanan yang merupakan jumlah singkong minimum yang harus dimiliki untuk menjaga kemungkinan keterlambatan datangnya singkong.

Tingkat kebutuhan singkong $(=\mathrm{d})$ di sini sama dengan jumlah pemesanan singkong per sekali pesan (= R) yakni $920 \mathrm{~kg}$. Lead time atau waktu yang dibutuhkan dari mulai memesan singkong hingga tiba di tempat produksi adalah 2 hari. Hal ini disebabkan singkong yang dipesan harus dicari terlebih dahulu ke beberapa pengepul agar jumlah singkong yang dibutuhkan dapat terpenuhi. Setelah singkong terkumpul, baru diangkut ke tempat produksi. Safety stock yang ditetapkan sebesar $400 \mathrm{~kg}$. Data tersebut diperoleh dari catatan agroindustri bulan November 2016.

Jadi, ROP dapat dihitung sebagai berikut:

$\mathrm{ROP}=(\mathrm{d} x \mathrm{~L})+\mathrm{SS}=(920 \mathrm{x} 2)+400=2.240$

Maknanya adalah apabila jumlah persediaan singkong sudah tersisa $2.240 \mathrm{~kg}$, maka Peuyeum Abas Sawargi perlu melakukan pemesanan singkong kembali agar persediaan singkong dapat terus terjaga.

Berdasarkan rumus (3) dan Tabel 2 diperoleh frekuensi pemesanan singkong $\mathrm{F}=198.750 / 3.264=61$. Jadi, frekuensi pemesanan adalah 61 kali dalam setahun atau 5 kali per bulan. Jika 1 tahun $=360$ hari, maka pemesanan singkong dilakukan 360/61 = 6 hari sekali.

Perbandingan biaya total persediaan aktual dengan yang beradasarkan EOQ, dihitung menggunakan rumus (4) sebagai berikut:

$$
\begin{aligned}
& \mathrm{TC}_{\text {EOQ }}=\frac{920}{3.264} \times 579.046+\frac{3.264}{2} \times 100 \\
& =326.411
\end{aligned}
$$

$$
\mathrm{TC}_{\mathrm{aktual}}=\frac{920}{920} \times 579.046+\frac{920}{2} \times 100
$$$$
=625.046
$$

$$
\begin{aligned}
& \text { BedaTC }=625.046-326.411=298.635 \text { atau } \\
& \frac{\mathbf{2 9 8 . 6 3 5}}{\mathbf{6 2 5 . 0 4 6}} \boldsymbol{x} \mathbf{1 0 0} \%=\mathbf{4 7 , 7 8} \% \text {. }
\end{aligned}
$$

Dengan demikian, biaya total persediaan terendah adalah $\mathrm{Rp}$ 35.422.205 dimana biaya tersebut tercapai akibat jumlah pemesanan singkong yang ekonomis sebesar $3.264 \mathrm{~kg}$. Penurunan biaya total persediaan adalah $\mathrm{Rp} 298.635$ atau 47,78\% dari biaya persediaan total aktualnya. Rekapitulasi perbandingan kondisi persediaan singkong agroindustri Peuyeum Abas Sawargi aktual dan yang berdasarkan EOQ dapat dilihat pada Tabel 4. Tampak bahwa jumlah pemesanan singkong sangat jauh berbeda antara yang

Tabel 4. Perbandingan Persediaan Kedelai Aktual Tahun 2016 dan yang Berdasarkan Model EOQ

\begin{tabular}{lcc}
\hline \multicolumn{1}{c}{ Uraian } & Aktual & EOQ \\
\hline Jumlah pemesanan & $920 \mathrm{~kg}$ & $3.264 \mathrm{~kg}$ \\
Frekuensi pemesanan & 214 & 61 \\
Jeda waktu antar tiap pemesanan & 2 hari & 6 hari \\
Biaya total persediaan & $\mathrm{Rp} \mathrm{625.046}$ & $\mathrm{Rp} \mathrm{326.411}$ \\
\hline Selisih biaya total persediaan & \multicolumn{2}{c}{$\mathrm{Rp} \mathrm{298.635=47,78 \%}$} \\
\hline
\end{tabular}


aktual dilakukan dengan yang menurut model EOQ yaitu 920 berbanding 3,264. Demikian pula frekuensi pemesanannya, yakni 214 berbanding 61. Hal ini menunjukkan bahwa mungkin teknik penyimpanan singkong lah penyebab utamanya. Seperti telah disebutkan sebelumnya bahwa singkong disimpan di tanah seluas kira-kira 100 meter persegi lalu ditutup terpal, sehingga daya tampungnya terbatas dan singkong hanya bertahan 3 hari. Akibatnya, pemesanan dilakukan berkali kali.

\section{KESIMPULAN}

1. Agroindustri Peuyeum Abas Sawargi menggunakan singkong jenis manggu dan mentega sebagai bahan baku utama pembuat tape singkong.

2. Tempat penyimpanan singkong yang berupa lahan sekitar 100 meter persegi dan terpal tebal sebaiknya diganti dengan kotak kayu yang dialasi serbuk kayu atau sekam yang lembab; atau bak dari bata yang dialasi pasir.

3. Jumlah persediaan singkong yang harus dimiliki adalah $3.264 \mathrm{~kg}$. Jumlah tersebut juga merupakan jumlah singkong yang ekonomis untuk dipesan dalam satu kali pemesanan singkong, sehingga agroindustri Peuyeum Abas Sawargi tidak harus melakukan pemesanan berkali-kali setiap akan melakukan proses produksi. Frekuensi pemesanan singkong dalam 1 tahun yang optimal adalah 61 kali.

4. Apabila jumlah persediaan singkong sudah tersisa $2.240 \mathrm{~kg}$, maka agroindustri perlu melakukan pemesanan kembali singkongnya.

5. Biaya total persediaan berdasarkan EOQ menurun hampir 48 persen dari biaya total aktualnya.

\section{DAFTAR PUSTAKA}

Assauri, S. 2004. Manajemen Produksi dan Operasi. Jakarta: Lembaga Penerbit Fakultas Ekonomi Universitas Indonesia.

Bargumono dan Suyadi Wongsowijaya. 2013. 9 Umbi Utama Sebagai Pangan Alternatif Nasional. Yogyakarta : Leutika prio.

Dinas Ketahanan Pangan dan Peternakan Provinsi Jawa Barat. 2014. Bioindustri Ubi Kayu. Diakses dari: http://dkpp.jabarprov.go.id/bioindustriubi-jalar/ [20/3/2017]

Fahmi, Irham. 2012. Manajemen Prodduksi dan Operasi. Bandung: Alfabeta

Ginting, Erliana. 2002. Teknologi Penanganan Pascapanen dan Pengolahan Ubikayu Menjadi Produk-Antara untuk Mendukung Agroindustri. Buletin Palawija No.4 Diakses dari: http://balitkabi.litbang.pertanian.go.id/wp -content/uploads/2017/03/bp_no4_2002_03.pdf [4/4/2017]

Pusat Data dan Sistem Informasi Pertanian. 2015. Analisis PDB Sektor Pertanian Tahun 2015. Diakses dari: http://pusdatin.setjen.pertanian.go.id/tiny mcpuk/gambar/file/Analisis_PDB_2015. pdf [16/2/2017]

Pusat Data dan Sistem Informasi Pertanian Kementerian Pertanian. Outlook Komoditas Pertanian Tanaman Pangan Ubi Kayu. 2016. Diakses dari http://epublikasi.setjen.pertanian.go.id/ep ublikasi [22/2/2017]

Rukmana, R. 1997. Ubi Kayu Budi daya dan Pascapanen. Bandung: Kanisius

Saparinto, Cahyo dan Hidayati, D. 2006. Bahan Tambahan Pangan. Yogyakarta: Kanisius.

Saragih, B. 2001. Agribisnis Paradigma Baru Pembangunan Ekonomi Berbasis Pertanian Kumpulan Pemikiran. Yayasan Mulia Persada Indonesia dan PT. Suveyor Indonesia. Diakses dari : http://www.ipard.com/art pada: 26 Maret 2017. 